\title{
Use of a psychiatric proforma for accident and emergency officers
}

\author{
Vivienne Schnieden, Stewart Good
}

\begin{abstract}
Objective-To devise a proforma for clinical documentation of psychiatric illness in an accident and emergency (A\&E) department, since $A \& E$ senior house officers (SHOs) have little psychiatric experience before starting their jobs.

Methods-History taking and mental state examinations by 16 SHOs were compared before $(n=50)$ and after $(n=50)$ the introduction of the proforma. Comments on the proforma were provided by all participants on a questionnaire.

Results-There was an improvement in documentation with the use of the proforma (Mann-Whitney $U$ test, $P<0.001$ ). The senior house officers found the proforma useful and supported further development of this initiative.

Conclusions-A standard form for documenting psychiatric history, designed according to local needs, is useful and should be available in A\&E departments. ( $f$ Accid Emerg Med 1996;13:180-183)
\end{abstract}

Key terms: psychiatric illness; history taking; proforma; accident and emergency department

The aim of the study was to see whether accident and emergency (A\&E) doctors found a psychiatric proforma useful while seeing patients with psychiatric problems and whether it enabled them to provide better documentation of a person's history and mental state for medicolegal purposes.

Many A\&E doctors have little experience in psychiatry other than that obtained as a medical student. A recent study ${ }^{1}$ showed that over one third of emergency physicians receive no training in the management of psychiatric emergencies. In the last five years only 14 out of $128 \mathrm{~A} \& \mathrm{E}$ senior house officers $(10.9 \%)$ in University College Hospital worked in psychiatry before working in the $\mathrm{A} \& \mathrm{E}$ department and most of those were on a vocational training scheme organised within the hospital, or on a self organised scheme.

The objectives for an A\&E doctor in assessing a psychiatric, or possibly psychiatric, patient are to decide on whether management of the condition is acute, whether the patient needs to see a psychiatrist immediately or in the near future, whether any physical treatment is indicated, and if the person is safe in terms of suicidal intent to be discharged from the department. The referral decisions of emergency room clinicians have become critical to successful intervention with such patients:
"For the troubled individual the decisions made during the emergency room visit determine the choice of a subsequent treatment plan and often influence the course of the problem or illness". ${ }^{2}$ An audit of emergency referrals from an A\&E department to the department of psychiatry found that most non-attenders were referred by letter by A\&E doctors. ${ }^{3}$ Various suggestions were made by the authors to improve this, including routine discussion between the A\&E doctors and a liaison psychiatrist, and the introduction of structured referral letters to include relevant information and improve the liaison between the two departments.

In order to facilitate history taking and mental state examination of psychiatric patients we designed a proforma with relevant headings (appendix) to act as an aide-memoire for the doctors. We paid particular attention to suicide risk and assessment and included the Pierce suicide intent scale. ${ }^{4}$ No additional teaching on psychiatry was given to the senior house officers, although following use of the proforma further teaching was requested and subsequently provided.

\section{Methods}

We compared 50 psychiatric assessments by $A \& E$ senior house officers made before the proforma was introduced with 50 assessments made after its introduction. The doctors were asked to fill in a proforma for each consecutive assessment they performed, and no restrictions were placed on its use. The study began in February 1993, and finished when the requisite number of assessments had been completed, in July 1993. We rated the assessments on the basis of various headings on the proforma as to whether the information given was adequate ( 2 points), inadequate ( 1 point), or absent ( 0 points). Headings included the presence of a diagnosis and whether the patient was referred to a psychiatrist who agreed with the diagnosis.

We asked all the A\&E doctors who had taken part in using the proforma to complete a questionnaire after they had left the department. They were asked to comment on their use of the proforma (never, rarely, sometimes, often, always) and whether it was useful (not useful, moderately useful, very useful) and in what ways it was useful (recording information, as an aide-memoire, as suicide risk assessment, and to facilitate communication with a psychiatrist). The senior house officers were asked for additional comments and whether they found the concept of a proforma useful for psychiatric assessments. 
Table 1 Usefulness of the proforma

\begin{tabular}{|c|c|c|c|}
\hline & $\begin{array}{l}\text { Not useful } \\
(\%)\end{array}$ & $\begin{array}{l}\text { Moderately useful } \\
(\%)\end{array}$ & $\begin{array}{l}\text { Very useful } \\
\text { (\%) }\end{array}$ \\
\hline Recording information & $6 \cdot 3$ & $81 \cdot 3$ & $12 \cdot 5$ \\
\hline $\begin{array}{l}\text { Aide-mémoire } \\
\text { Suicide risk assessment }\end{array}$ & $\begin{array}{l}6 \cdot 3 \\
0 \cdot 00\end{array}$ & $\begin{array}{l}25 \cdot 0 \\
56 \cdot 3\end{array}$ & $\begin{array}{r}68 \cdot 8 \\
43 \cdot 8\end{array}$ \\
\hline $\begin{array}{l}\text { Communication with } \\
\text { psychiatrist }\end{array}$ & $31 \cdot 2$ & $37 \cdot 3$ & $31 \cdot 3$ \\
\hline
\end{tabular}

\section{Results}

Sixteen $A \& E$ doctors filled in the questionnaire (response rate $100 \%): 19 \%(n=3)$ rarely used the proforma, $31 \%(n=5)$ sometimes used it, and $50 \%(n=8)$ used it often (table 1$)$. Fifteen $(94 \%)$ approved of the concept of a proforma.

Our analysis of the differences between the history and mental state assessment obtained before and after the introduction of the proforma is shown in table 2 .

Using the Mann Whitney $U$ test, a comparison of the scores for the 50 histories and mental state assessments made before the introduction of the proforma with the 50 obtained from completed proformas showed that they were significantly different $(\mathrm{U}=105.5, \mathrm{P}<0.001$. The median score of 50 assessments before the introduction of the proforma was 18 (range 5 to 38 ) and after the introduction, 33 (range 5 to 45 ).

\section{Discussion}

The comments included suggestions on format and style in terms of where more space was needed. One of the main difficulties experienced was to do with the amount of time perceived to fill in the proforma. Some of the more detailed background information headings were not thought to be relevant to an A\&E setting. These difficulties could be addressed by the use of a truncated proforma and by emphasising that some headings do not need to be filled in routinely but act as an aidememoire. This is how $69 \%$ of the SHOs (11 out of 16) found the proforma most useful.

Certain items were not relevant to the $A \& E$ setting: for example very few doctors documented psychosexual history or personality traits with or without the proforma unless there was a particular indication. The Pierce intent scale $^{4}$ was used in seven cases, reflecting the fact that relatively few patients for whom the SHOs chose to use the proforma had deliberately harmed themselves. However all the $A \& E$ doctors found that the proformas were either moderately or very useful in helping with suicide risk assessment.

An interactive computer program, where different headings would appear according to information entered, would be another way forward and it has been shown that use of the computer for teaching gave results at least as good as when it was used for direct feedback. This may be highly relevant for those who are apprehensive about the real time use of diagnostic computers in a clinical setting. ${ }^{5}$
Table 2 Under each heading a score of 2, 1, or 0 was given for adequate, inadequate, or no completion of the record

\begin{tabular}{lll} 
& \multicolumn{2}{l}{ Score (Max 100 points) } \\
\cline { 2 - 3 } & $\begin{array}{l}\text { Before proforma } \\
\text { (50 patients) }\end{array}$ & $\begin{array}{l}\text { After proforma } \\
\text { (50 patients) }\end{array}$ \\
\hline History & & \\
Reason for presentation & 73 & 76 \\
Presenting complaint & 73 & 69 \\
Biological features of & 33 & 62 \\
depression & & \\
Family psychiatric history & 20 & 51 \\
Personal history & 7 & 39 \\
Past medical history & 60 & 75 \\
Medication & 68 & 76 \\
Past psychiatric history & 48 & 87 \\
Psychosexual history & 7 & 12 \\
Substance abuse & 36 & 67 \\
Antisocial behaviour & 11 & 52 \\
Social circumstances & 40 & 54 \\
Personality & 3 & 14 \\
Mental state & & \\
Appearance and behaviour & 47 & 82 \\
Talk & 47 & 93 \\
Affect/mood & 31 & 62 \\
Suicidal ideation and & 46 & 87 \\
intent & & 81 \\
Thought content & 33 & 92 \\
Thought possession & 25 & 86 \\
Obsessions/compulsions & 4 & 90 \\
Abnormal perceptions & 49 & 64 \\
Cognitive state & 12 & 69 \\
Explanatory model/insight & 23 & 86 \\
Presence of A\&E diagnosis & 74 & 46 of 7 referred) \\
Agreement between A\&E & 46 & \\
and psychiatric & 6 of 13 referred) & \\
diagnoses & & \\
\hline
\end{tabular}

The improvement in scores obtained after the introduction of the proforma suggests that a more adequate history and mental state assessment is obtained by its use. This has implications for medicolegal use and would ensure that relevant basic data are recorded by even the most junior $A \& E$ doctor. Mental state examination was vastly improved by using the proforma. This has particular relevance for psychiatrists, who often find the mental state examination in an initial presentation is a useful aid to diagnosis. An accurate and consistent standard measure of mental state is also a useful way of monitoring patients who may present periodically to emergency departments. We are aware that the differences that occurred after the introduction of the proforma may have been due to an increased value placed on documentation rather than the value of the questions themselves.

Eleven of the $16 \mathrm{~A} \& \mathrm{E}$ doctors (69\%) thought the proforma enhanced communication with the psychiatrist. Its use also increased the agreement between A\&E doctors' and psychiatrists' diagnoses and would therefore appear to have an educational value. We recommend the implementation of a standard form of this kind in all A\&E departments. It should be designed according to particular local needs and would therefore need regular review and monitoring of its value. This would also promote continued communication between psychiatric and $\mathrm{A} \& \mathrm{E}$ departments. We acknowledge help given by the staff of the Department of
Accident and Emergency Medicine, University College Hospital, London. 


\section{Appendix}

\section{PSYCHIATRIC PROFORMA FOR USE IN A\&E}

\section{History}

Reason for Presentation

Presenting Complaint:

Biological Features of Depression:

Family History especially psychiatry:

Personal History:

Child development, Education

Occupation

Past Medical history:

Medication:

Past Psychiatric History: Where? When? What treatment?

Psychosexual:

Substance Abuse:

Nicotine

Alcohol

Recreational Drugs

Antisocial Behaviour eg truant/prison:

Social Circumstances - housing/debt/family support:

Personality:

Abnormal perceptions: Body/Self/Environment:

Illusions

Hallucinations

Pseudohallucinations

Ideas of reference

Objectory hallucinations

Cognitive State:

Orientation

Attention

Memory

Immediate recall

Short term memory

Long term memory

Intelligence

Explanatory Model (Insight):

Does the patient think they are ill?

How do they think they may best be helped?

Provision Diagnosis ( $A$ \& E):

Provisional Diagnosis (Psychiatrist)
Mental State Examination - Use Examples

Appearance and General Behaviour:

Appearance

Manner

Motility

Talk(Form):

Mute/stammer/stutter

Flight of ideas

Rate

Amount

Formal thought disorder eg neologisms/flight of ideas/loosening of associations/puns GIVE EXAMPLES

Affect/Mood:

Prevailing mood state

Labile/flat/incongruous/perplexed

Morbid thoughts

Suidical Ideas/Intent: - Please use Pierce Intent Scale on page 4

Thought Content: Body/Self/Environment:

Preoccupations

Delusions/false beliefs

Ideas of reference

Possession of Thought:

? Thought insertion/withdrawal/broadcasting

EXAMPLES

Obsessions/Compulsions: eg checking

Pierce Suicide Intent Score Scale

Circumstances related to suicidal attempt

Isolation

0 Somebody present

1 Somebody nearby or in contact (as by phone)

2 No-one nearby, or in contact

Timing

0 Timed so that intervention is probable

1 Timed so that intervention is not likely

2 Timed so that intervention is highly unlikely

Precautions against discovery $\quad 0$ No precautions

and/or intervention

1 Passive precautions eg avoiding others, but doing nothing to prevent their

intervention (alone in room, door unlocked)

2 Active precautions, such as locking doors

Acting to gain help during or after the attempt

0 Notified potential helper regarding attempt

1 Contacted but did not specifically notify potential helper regarding the attempt

2 Did not contact or notify potential helper

Final acts in anticipation of $\quad 0$ None

death

1 Partial preparation or ideation

2 Definite plans made eg changes in a will, taking out insurance

Suicide note

0 Absence of note

1 Note written but torn up

2 Presence of note 


\section{Self report}

Patient's statement of lethality

0 Thought what he had done would not kill him

1 Unsure if what he had done would kill him 2 Believed that what he had done would kill him

Stated intent

Premeditation

Reaction to the act

0 Did not want to die

1 Uncertain or did not care if he lived or died

2 Did want to die

0 Impulsive, no premeditation

1 Considered act for less than one hour

2 Considered act for less than one day

3 Considered act for more than one day

0 Patient glad he has recovered

1 Patient uncertain whether he is glad or sorry

2 Patient sorry he has recovered

Risk

Predictable outcome in terms

of lethality of patient's act and

circumstances known to him

Would death have occurred

without medical treatment?

Suicide intent score

\section{Survival certain}

1 Death unlikely

2 Death likely or certain

0 No

1 Uncertain

2 Yes

Low: $\quad 0-3$

Moderate: 4-10

High: $\quad 11+$
1 Buzan RD, Weissberg MP. Suicide: risk factors and the therapeutic considerations in the Emergency Department. $f$ Emerg Med 1992;10:335-43.

2 Marson DC, McGovern MP, Pomp HC. Psychiatric decision making in the emergency room: a research overview. Am f Psychiatry 1988;145:918-25.

3 Schnieden V, Gourdie A, Bell G. Emergency psychiatric referrals. Med Audit News 1991;1:57-8.

4 Pierce DW. Suicidal intent in self injury. Br $\mathcal{F}$ Psychiatry 1977;130:377-85.

5 Dombal de FT, Dallos V, McAdam WAF. Can computer aided teaching packages improve clinical care in patients with acute abdominal pain? BMF 1991;302:1495-7. 